\title{
Quality control guidelines for clinical-grade human induced pluripotent stem cell lines
}

\author{
Stephen Sullivan ${ }^{\ddagger 1}$, Glyn N Stacey ${ }^{\ddagger 2}$, Chihiro Akazawa ${ }^{3}$, Naoki Aoyama ${ }^{4}$, Ricardo \\ Baptista $^{5}$, Patrick Bedford ${ }^{6}$, Annelise Bennaceur Griscelli ${ }^{7}$, Amit Chandra ${ }^{8}$, Ngaire \\ Elwood $^{9,10}$, Mathilde Girard ${ }^{11}$, Shin Kawamata ${ }^{12}$, Tadaaki Hanatani ${ }^{13}$, Theodoros Latsis ${ }^{7}$, \\ Stephen Lin ${ }^{14}$, Tenneille E Ludwig ${ }^{15}$, Tamara Malygina ${ }^{16}$, Amanda Mack ${ }^{17}$, Joanne C \\ Mountford ${ }^{18}$, Scott Noggle ${ }^{19}$, Lygia V Pereira ${ }^{20}$, Jack Price ${ }^{21}$, Michael Sheldon ${ }^{22}$, Alok \\ Srivastava ${ }^{23,24}$, Harald Stachelscheid ${ }^{25}$, Shaji R Velayudhan ${ }^{23,24}$, Natalie J Ward ${ }^{5}$, Marc L \\ Turner ${ }^{1,5,18}$, Jacqueline Barry ${ }^{1,5}$ \& Jihwan Song ${ }^{\star 1,1,26}$ \\ ${ }^{1}$ Global Alliance for iPSC Therapies (GAiT), The Jack Copland Centre, Edinburgh, UK \\ ${ }^{2}$ International Stem Cell Banking Initiative, 2 High St, Barley, Hertfordshire, UK \\ ${ }^{3}$ Department of Biochemistry and Biophysics, Graduate School of Health Care Sciences, Tokyo Medical and Dental University \\ (TMDU), Tokyo, Japan \\ ${ }^{4}$ Japan Agency for Medical Research and Development (AMED), Chiyoda-ku, Tokyo, Japan \\ ${ }^{5}$ Cell \& Gene Therapy Catapult, 12th Floor Tower Wing, Guy's Hospital, London, UK \\ ${ }^{6}$ Centre for Commercialization of Regenerative Medicine (CCRM), Toronto, ON, Canada \\ ${ }^{7}$ APHP-Hopital Paul Brousse Université Paris Sud/ESteam Paris Inserm UMR 935, Villejuif, France \\ ${ }^{8}$ Centre for Biological Engineering, Loughborough University, Holywell Park, Loughborough, UK \\ ${ }^{9}$ Cord Blood Research, Murdoch Children's Research Institute, Melbourne, VIC 3052, Australia \\ ${ }^{10}$ Department of Paediatrics, University of Melbourne, Parkville, Victoria 3052, Australia \\ ${ }^{11}$ Yposkesi, 2 Rue Henri Auguste Desbruères, 91100 Corbeil-Essonnes, France \\ ${ }^{12}$ Foundation Biomedical Research and Innovation (FBRI), Research and Development Center for Cell Therapy, Chuo-ku, Kobe, \\ Japan \\ ${ }^{13}$ Center for iPS Cell Research and Application (CiRA), Kyoto University, Kyoto, Japan \\ ${ }^{14}$ California Institute for Regenerative Medicine (CIRM), Lake Merritt Plaza, 1999 Harrison Street STE 1650, Oakland, CA, USA \\ ${ }^{15}$ WiCell Research Institute (WiCell Stem Cell Bank), Madison, WI 53719, USA \\ ${ }^{16}$ Optec LLC, Inzhenernaya Str., 28 Novosibirsk, 630090, Russia \\ ${ }^{17}$ Fujifilm Cellular Dynamics International, 525 Science Dr., Madison, WI 53711, USA \\ ${ }^{18}$ Advanced Therapeutics, Scottish National Blood Transfusion Service, Edinburgh, UK \\ ${ }^{19} \mathrm{New}$ York Stem Cell Foundation Laboratories, New York, NY 10032, USA \\ ${ }^{20}$ Department of Genetics and Evolutionary Biology, Institute of Biosciences, University of São Paulo, São Paulo, Brazil \\ ${ }^{21}$ UK Stem Cell Bank, National Institute for Biological Standards and Control, Hertfordshire, UK \\ ${ }^{22}$ Department of Genetics, Rutgers, The State University of New Jersey, Piscataway, NJ 08854-8009, USA \\ ${ }^{23}$ Department of Haematology, Christian Medical College, Vellore- 632004, Tamil Nadu, India \\ ${ }^{24}$ Centre for Stem Cell Research, Christian Medical College, Vellore- 632004, Tamil Nadu, India \\ ${ }^{25}$ Charité - Universitätsmedizin Berlin, Berlin Institute of Health and Berlin-Brandenburg Center for Regenerative Therapies, Berlin \\ 13353, Germany \\ ${ }^{26}$ Department of Biomedical Science, CHA Stem Cell Institute, CHA University, Seongnam-si, Gyeonggi-do, Republic of Korea \\ *Author for correspondence: jsong@cha.ac.kr \\ ${ }^{\ddagger}$ Authors contributed equally.
}

Use of clinical-grade human induced pluripotent stem cell (iPSC) lines as a starting material for the generation of cellular therapeutics requires demonstration of comparability of lines derived from different individuals and in different facilities. This requires agreement on the critical quality attributes of such lines and the assays that should be used. Working from established recommendations and guidance from the International Stem Cell Banking Initiative for human embryonic stem cell banking, and concentrating on those issues more relevant to iPSCs, a series of consensus workshops has made initial recommendations on the minimum dataset required to consider an iPSC line of clinical grade, which are outlined in this report. Continued evolution of this field will likely lead to revision of these guidelines on a regular basis.

First draft submitted: 20 July 2018; Accepted for publication: 15 August 2018; Published online: 12 September 2018 
Keywords: clinical-grade induced pluripotent stem cells $\bullet$ good manufacturing practice $\bullet$ minimum testing requirements • quality control • quality control attributes

\section{Comparability of 'clinical-grade' induced pluripotent stem cells}

Since the derivation of human induced pluripotent stem cells (iPSCs) [1], there has been much interest in the development of clinical-grade cell lines suitable for use as a starting material for the manufacture of novel cellular therapies [2]. Realization of this objective is contingent on the ability to demonstrate comparability between cell lines, and the products manufactured therefrom, derived from different donors (whether autologous or allogeneic), between those derived by different manufacturers and between different passages of the same cell line. Demonstration of comparability is dependent on agreement on the critical quality attributes (CQAs), in other words, those physical, chemical or biological properties that should be within an appropriate limit, range or distribution needed to ensure quality and safety of the product for its intended use. In addition, consideration needs to be given to the assays that should be used to measure these parameters and the standards and tolerances that should be applied [3].

While there is general agreement that CQAs in respect of iPSCs include identity, microbiological sterility, genetic fidelity and stability, viability, characterization and potency, a survey of 16 facilities involved in iPSC manufacturing showed wide variation in parameters, assays and standards, highlighting differences between institutions as to what would constitute a clinical-grade iPSC line.

Consequently, a series of workshops was convened in order to build greater communal understanding and agreement about what should be considered CQAs for clinical-grade iPSC lines and what quality control assays should be applied. The first of these workshops was held in Boston (MA, USA) on 18 June 2017, where it was agreed that the work of the International Stem Cell Banking Initiative provided a critical starting point [4], but that there were some areas where further clarification was required. The second workshop was held in Sheffield (UK) on 5 October 2017 and discussed each CQA and applicable assays and standards, and whether these should be mandatory, for information only, or not required.

This report aims to summarize the key conclusions from the two workshops and to provide an international consensus on CQAs and minimum testing requirements for clinical-grade iPSC lines across identity, microbiological sterility, genetic fidelity and stability, viability, characterization and potency. A summary of the conclusions of this workshop is also included in Table 1 , with explanatory comments.

\section{Critical quality attributes \& recommended test methods for clinical-grade iPSC lines}

It is easier to achieve agreement around common standards at the start of development of a field rather than try to impose them once the field starts to mature, when individual groups have implemented their own standards and controls. Consequently, the Global Alliance for iPSC Therapies (GAiT) [5] facilitates the development of global clinical-grade iPSC standards by community engagement and consensus building as the first step in the development of an international network of clinical-grade iPSC haplobanks, which itself will support the global application of iPSC-derived cellular therapeutics.

When considering the rationale for setting clinical-grade iPSC critical quality attributes, each test should be considered for the information it provides with regard to risk during clinical translation and to comprehensively understand the consequences that may arise from such testing. All testing on seed, master and working cell banks should be performed by accredited and licensed laboratories where available. Where this is not possible, validation and qualification of in-house assays and where possible comparability exercises with other laboratories should be undertaken.

\section{Identity}

The risk of inadvertent switching of lines and cross contamination of lines with other cell lines necessitates a stringent assay for cell line identification [6,7].

\section{Short tandem repeat analysis}

Single tandem repeat (STR) genotyping of source tissue or cells and iPSC seed and master cell banks is recommended using a commercially available kit performed by an accredited laboratory. 


\begin{tabular}{|c|c|c|c|c|}
\hline Attribute & Test & Status & $\begin{array}{l}\text { Recommended analytical } \\
\text { method }\end{array}$ & Acceptance criteria \\
\hline Identity & STR & Mandatory & $\begin{array}{l}\text { STR profiles } \\
\text { Performed by accredited } \\
\text { laboratory on donor starting } \\
\text { material and lots }\end{array}$ & Identical \\
\hline \multirow[t]{2}{*}{ Microbiological sterility } & Mycoplasma & Mandatory & $\begin{array}{l}\text { Qualified qPCR or culture } \\
\text { (broth/agar or Vero } \\
\text { inoculation/DNA stain) method } \\
\text { Use of pharmacopeial methods } \\
\text { USP }<63>\text {, Ph.Eur.2.6.7 and } \\
\text { JP17 }<\text { G3 }>\end{array}$ & Negative \\
\hline & Bacteriology & Mandatory & $\begin{array}{l}\text { Use of pharmacopeial methods } \\
\text { USP }<71>\text { and }<61>\text {, } \\
\text { Ph.Eur.2.6.27 and 2.6.1, } \\
\text { JP17 }<4.05>\text { and }<4.06>\end{array}$ & Negative \\
\hline Endotoxin & Endotoxin & Mandatory & $\begin{array}{l}\text { Use pharmacopeial methods } \\
\text { USP }<85>\text {, Ph.Eur.2.6.14, } \\
\text { JP17 }<4.01>\end{array}$ & Negative \\
\hline \multirow[t]{4}{*}{ Genetic fidelity \& stability } & Residual vector testing & Mandatory & $\begin{array}{l}\text { Appropriate specific assay to be } \\
\text { used }\end{array}$ & Negative \\
\hline & Karyotype & Mandatory & G Banding & $\begin{array}{l}\text { Normal (diploid) } \\
\geq 20 \text { metaphases }\end{array}$ \\
\hline & SNP arrays & For information & & \\
\hline & $\begin{array}{l}\text { WGS/WES cancer associated } \\
\text { panels and other genetic, and } \\
\text { disease marker analysis }\end{array}$ & For information & & \\
\hline \multirow[t]{3}{*}{ Characterization } & Flow cytometry & Mandatory & $\begin{array}{l}\text { A minimum of two markers } \\
\text { from an accepted panel (SSEA4, } \\
\text { TRA1-60, OCT4, Nanog, etc.). } \\
\text { Use pharmacopeial methods } \\
\text { USP }<1027>\text {, Ph.Eur.2.7.24 }\end{array}$ & $\begin{array}{l}\text { Markers should typically be } \\
\text { positive on }>70 \% \text { of cells in the } \\
\text { Master Cell Bank }\end{array}$ \\
\hline & Immuno-cytochemistry & For information & & \\
\hline & Differentiated cells & Not required, for information & & \\
\hline Potency & Phenotypic & Mandatory & $\begin{array}{l}\text { EB formation and/or directed } \\
\text { differentiation. } \\
\text { Teratoma formation not } \\
\text { required as a potency assay }\end{array}$ & $\begin{array}{l}\text { Demonstration of cells from all } \\
\text { three germ layers }\end{array}$ \\
\hline & Molecular & For information & Pluritest $^{T M}$ or hPSC Scorecard ${ }^{T M}$ & \\
\hline
\end{tabular}

\section{Microbiological sterility}

Due to the nature of the stem cell based products - living cells that themselves cannot be sterilized - microbiological sterility is of the highest importance in delivering therapies. An overall microbiological control strategy that will not only rely on finished product testing is recommended.

\section{Mycoplasma}

iPSC banks should be tested for mycoplasma using US, European, Japanese pharmacopeia or otherwise nationally accredited pharmacopeia methods. Potential limitations of particular tests are sensitivity and test inhibition [8]. 
Challenge or spiking tests for these tests will be listed in pharmacopeia and should be carried out. The tests could be PCR-, broth-, culture- or VERO incubation-based.

\section{Bacteriology}

Standard bacterial and fungal sterility tests recommended in pharmacopeia in different countries are similar. The tests could be broth- or culture-based but must be recommended by pharmacopeia for the jurisdiction in which the work is being undertaken.

While molecular methods could be used in addition to broth- and culture-based tests, they cannot be used instead of pharmacopeia recommended tests.

\section{Viral testing}

All mandatory tests for human adventitious agents should be performed (i.e., testing for hepatitis B virus, hepatitis $\mathrm{C}$ tests [HCV], human immunodeficiency virus and nucleic acid testing). In the case of non-xeno-free culture reagents, appropriate nonhuman adventitious agent testing should be considered.

\section{Endotoxin}

While a pharmacopeia accredited test for endotoxin is suggested, limits to sensitivity and specificity and use of appropriate international standard reference materials should be considered.

\section{Genetic fidelity \& stability}

Genetic change in iPSCs, or a product derived therefrom, is of concern as it raises potential hazards around cell transformation and the risk of causing malignancy in patients.

\section{Residual vector testing}

Testing for the presence of reprogramming vectors is considered mandatory as there are potential safety issues if vectors have integrated into the host genome.

Initial recommendations cover reprogramming by episomal vectors [9,10], as currently, this is the reprogramming technique most commonly considered for generating clinical-grade iPSC lines. Procedures for showing transgene clearance by Sendai virus or mRNA methods are currently being developed and may be included in the second iteration of these guidelines. As there are no accredited laboratories that offer this assay for iPSCs, particular attention should be paid to the design and validation of any 'in-house' assays used for this purpose.

It is recommended that an acceptance threshold of $\leq 1$ plasmid copy per 100 cells is used, similar to that used for high-quality research-grade iPSC line collections. Clearance to this level must be demonstrated in seed and master cell banks.

Further considerations include:

- Testing platform: to increase accuracy and reduce the possibility of false-positive results, the use of quantitative PCR using sequence-specific labeling chemistry, for example, Taqman ${ }^{T M}$ is recommended, rather than those such as $\mathrm{SYBR}^{\mathrm{TM}}$ green that bind all dsDNA.

- Two different regions, common to all plasmids used in the reprogramming system, should be chosen as specific targets, for example, OriP, EBNA, CAG sequences.

- A standard curve should be prepared in a carrier of gDNA rather than water to accurately represent the test reactions. Ideally, gDNA from a well-characterized human pluripotent stem cell (hPSC) line (e.g., WA09) should be used.

- Internal reference gDNA sequences should be incorporated to allow quantification, for example, RNaseP, hTERT. This is particularly important for the calculation of plasmid copies per cell.

- Sensitivity should allow detection of $\leq 1$ plasmid copy per 100 cells and standard curve(s) should be prepared to include samples at least 1 log below this level to demonstrate the limit of detection.

\section{Karyotype}

Standard methods, procedures and recommended terms for the reporting of the karyological analysis of researchgrade human pluripotent stem cells have previously been published [4]. Long-term culture of human embryonic stem cells (hESCs) has shown that pluripotent stem cells (PSCs) can accumulate culture-driven mutations [11] and 
it has been proposed that iPSCs may be more genetically unstable than other PSC populations [12]; therefore, particular attention should be paid to genomic integrity [13].

To test for karyotype, it is recommended that a representative aliquot be resuscitated according to best practice and cultured for 48-72 h before cells are harvested for karyotypic analysis. A 20-metaphase karyotypic analysis is recommended since it is a universal clinical standard and is widely accepted by regulators worldwide, giving $95 \%$ certainty of diploidy $[14,15]$.

If an abnormality is found in the first 20 karyotypes, the analysis should be repeated on a fresh sample. If the abnormalities are also detected in the second sample then the line itself is deemed abnormal.

It is recommended that repeated abnormalities, in other words, an abnormality has been seen in a line before, be recorded when listing the karyotypic data.

\section{Single nucleotide polymorphism arrays}

Single nucleotide polymorphism (SNP) arrays offer > 50-times higher resolution than standard karyology [16] and so enable detection of subchromosomal changes and copy-neutral loss of heterozygosity events that have previously been identified in hESC cultures and can also signify cellular transformation. SNP arrays are now standard practice as a first-tier test for diagnostic clinical diagnostic cytogenetics.

It is recommended that SNP analysis be carried out by an accredited laboratory for information only.

\section{Genetic \& disease marker analysis}

Whole genome analysis and other genetic and disease marker analysis will not be mandatory but when voluntarily collected can be reported 'for information only'. The current inability to clinically interpret a large portion of such data can cause significant confusion. Furthermore, regulators do not currently require this information. It is recommended that whole exome sequencing is performed to the highest level of coverage and depth available (ideally $\geq 50 \times$ mean coverage) as a process quality measure and planned to watch developments in the ISCI discussions on functional associations of genetic change with in vitro and in vivo cell behavior.

There is currently some concern in the scientific community about the relevance of specific cancer-associated changes that might occur during iPSC derivation and culture. For example, mutations in TP53 have been reported [17,18]; however, the clinical significance of these changes in PSC is unclear and as such it is advised that WGS/WES data are screened using information from collated panels of such mutations, for example, COSMIC or Shibata lists $[19,20]$, and that these data be retained for information with the cell line file and also submitted to a database of clinical iPSC lines. In this way, scientific evidence of the impact of these mutations can be correlated with derivation, culture and differentiation capacity. We acknowledge that the specific risks posed by genetic mutations may differ dependent on context and final differentiated cell type which should be considered by final product manufacturers.

\section{Viability}

Measurement of cell viability is important to giving an appropriate and consistent dosage of cells to the patient. A technique for assessing cell viability should be selected that gives a suitable read out for the cell type in question.

\section{Viability}

It is recommended that viability should be quantified using a validated method, and that a cell viability test be carried out on iPSC cultures $48 \mathrm{~h}$ after resuscitation.

\section{Doubling time}

Doubling time provides useful information and can provide assurance of genetic stability over time but is not considered mandatory. It is recommended that the number of passages that the cells have undergone also be recorded; however, as passage ratios and seeding density can dramatically vary, cumulative population doublings is a more accurate reflection of the replicative history of the cells and should be used wherever possible.

\section{Cell debris}

Recording the presence or absence of cell debris is not required, as it is highly unlikely that it will have an impact on the final medicinal product. 


\section{Characterization}

From a safety perspective, it is important to characterize iPSCs to manage the risk associated with the presence of atypical or spontaneously differentiating cells.

\section{Flow cytometry}

Immunophenotyping with a minimum of two markers from the standard hPSC panel (positive for OCT4, TRA1-60, TRA-1-81, SSEA-3, SSEA-4, Sox2, Nanog) is mandatory. A combination of one intracellular (e.g., OCT4, SOX2 or Nanog) and one extracellular (e.g., SSEA-4 or TRA-1-60) should be used. Additional markers can also be included for information only. Positive marker expression profiles consistent with hPSC should be seen in $>70 \%$ of cells. Due to the subjectivity associated with setting flow threshold markers, there is a need to agree a common fixed and validated analysis template.

Characterization data for information and specifications for seed stocks of research-grade hPSC lines have previously been published [4] and it is recommended that this is used for information only.

A description of the culture regime used should be supplied with the flow cytometry data, as different culture systems influence relative expression patterns of pluripotent stem cell markers.

\section{Immunocytochemistry}

Immunocytochemistry for human PSC-specific markers is not mandatory, but if such characterization is undertaken, a record of such analysis should be retained for information only. Again, a description of the culture regime would also be helpful as this will influence relative expression levels. As for flow analysis, a combination of intracellular and extracellular markers is preferred.

\section{Differentiated cells}

Characterizing the identity of differentiated cells within the iPSC line is not recommended.

\section{Potency}

Potency is the qualitative measure of the biological activity of the cells, which is linked to relevant biological properties of the product. Risks associated with inadequate control of iPSC potency include lack of product efficacy, tissue chimerism and inappropriate cell function.

\section{Phenotypic pluripotency assays}

Self-renewal and undifferentiated cell markers are often used as surrogates to assess pluripotency but there is a need to functionally test for pluripotency. Embryoid body formation or directed differentiation of monolayer cultures to produce cell types representative of all three embryonic germ layers should be performed. Any data that demonstrate marker expression for endoderm, mesoderm and endoderm are sufficient.

Culture conditions can also affect differentiation potential and should be reported with the pluripotency data. Propensity of individual lines for differentiating into different lineages can be captured and reported for information but is not mandatory.

The teratoma formation/severe combined immune-deficient (SCiD) mouse injection assay for pluripotency is not mandatory as it does not give an acceptable degree of reproducibility [4,21]. Repeated assessment with this test may not be feasible for routine testing due to the high expense of breeding and keeping such immunocompromised lab animals is also not likely to garner ethical approval [22].

\section{Molecular pluripotency assays}

Molecular-, mRNA array- or RNA-Seq-based gene expression assays that may predict functional pluripotency are available as commercial services. The most widely accepted and available of these are Pluritest ${ }^{\mathrm{TM}}$ [23] and hPSC ScoreCard ${ }^{T M}$ [24]. Demonstration of pluripotency by one of these methods is for information at this stage in the development of the field.

\section{Conclusion}

This paper reports an international consensus on CQAs and minimum testing requirements for clinical-grade iPSC lines. Further testing is suggested for information. However, it should be noted that the science in this field 
continues to advance very quickly and these guidelines will continue to evolve in line with developments in scientific understanding and developments in technology and best practice.

The Global Alliance for iPSC Therapies is committed to continue building consensus around standards for iPSC manufacturing in order to accelerate the development and delivery of the next generation of cellular therapies to the benefit of patients worldwide.

\section{Future perspective}

If the potential of iPSC-derived therapeutics is to be realized, it is critical that the starting materials (the clinical-grade iPSC lines), the manufacturing processes and the cellular therapy products themselves are extensively characterized and understood. Demonstration of comparability between different iPSC lines (and the products derived therefrom) requires agreement on CQAs and standardization of the analytics used to evaluate these. In a fast-moving field such as this, these standards are bound to evolve in response to improvement in our scientific understanding and experience in analytic and process development, manufacturing and eventual clinical application. This consensus view should therefore be seen as initial and provisional but is likely to require frequent revision in the years to come.

The development of automation, closed cell systems and validated testing protocols should support the industrialization of manufacture of clinical-grade iPSC lines either for autologous or allogeneic use [25]. Demonstration of comparability, standardization and validation of such systems will be critical to the global adoption of iPSC-derived therapies.

\section{Executive summary}

- Demonstration of comparability of clinical-grade induced pluripotent stem cells (iPSCs) is essential and requires an agreement of critical quality attributes, validation of suitable assays and the development of standards.

- Consensus building to standardize iPSC manufacturing should assist efficient translation of iPSC technology to clinics worldwide.

- A series of workshops was convened with the aim of agreeing upon an initial set of recommendations around testing for identity, sterility, genetic fidelity and stability, viability, characterization and potency.

- Guidance for approved QC testing methods for some of these parameters is available from the relevant sections of pharmacopeia and these have been listed. For other parameters, the community will now need to develop appropriate standards and validation approaches.

- Periodic revision of the criteria will be necessary, in line with developments in scientific understanding, technology and best practice.

Financial \& competing interests disclosure

This work was supported by a grant awarded to J Song from the Korea Health Industry Development Institute (KHIDI), funded by the Ministry of Health and Welfare (HI15C3042), Republic of Korea. The authors have no other relevant affiliations or financial involvement with any organization or entity with a financial interest in or financial conflict with the subject matter or materials discussed in the manuscript apart from those disclosed.

No writing assistance was utilized in the production of this manuscript.

\section{Open access}

This work is licensed under the Attribution-NonCommercial-NoDerivatives 4.0 Unported License. To view a copy of this license, visit http://creativecommons.org/licenses/by-nc-nd/4.0/

\section{References}

1. Takahashi K, Tanabe K, Ohnuki M et al. Induction of pluripotent stem cells from adult human fibroblasts by defined factors. Cell 131(5), 861-872 (2007).

2. Barry J, Hyllner J, Stacey G, Taylor CJ, Turner M. Setting up a haplobank: issues and solutions. Curr. Stem Cell Rep. 1(2), 110-117 (2015).

3. Andrews PW, Cavagnaro J, Deans R et al. Harmonizing standards for producing clinical-grade therapies from pluripotent stem cells. Nat. Biotechnol. 32(8), 724-726 (2014).

4. Andrews PW, Baker D, Benvinisty N et al. Points to consider in the development of seed stocks of pluripotent stem cells for clinical applications: International Stem Cell Banking Initiative (ISCBI). Regen. Med. 10(2 Suppl.), 1-44 (2015). 
5. The Global Alliance for iPSC Therapies. www.gait.global

6. MacLeod RA, Dirks WG, Matsuo Y, Kaufmann M, Milch H, Drexler HG. Widespread intraspecies cross-contamination of human tumor cell lines arising at source. Int. J. Cancer 83(4), 555-563 (1999).

7. Gymrek M, McGuire AL, Golan D, Halperin E, Erlich Y. Identifying personal genomes by surname inference. Science 339(6117), 321-324 (2013).

8. Stacey GN, Auerbach JM. Quality control procedures for stem cell lines. In: Culture of Human Stem Cells. Freshney RI, Stacey GN, Auerbach JM (Eds). John Wiley \& Sons, Inc., NJ, USA, 1-21 (2007).

9. Chou BK, Mali P, Huang X et al. Efficient human iPS cell derivation by a non-integrating plasmid from blood cells with unique epigenetic and gene expression signatures. Cell Res. 21(3), 518-529 (2011).

10. Dowey SN, Huang X, Chou BK, Ye Z, Cheng L. Generation of integration-free human induced pluripotent stem cells from postnatal blood mononuclear cells by plasmid vector expression. Nat. Protoc. 7(11), 2013-2021 (2012).

11. International Stem Cell Initiative, Amps K, Andrews PW et al. Screening ethnically diverse human embryonic stem cells identifies a chromosome 20 minimal amplicon conferring growth advantage. Nat. Biotechnol. 29(12), 1132-1144 (2011).

12. Tapia N, Scholer HR. Molecular obstacles to clinical translation of iPSCs. Cell Stem Cell 19(3), 298-309 (2016).

13. Peterson SE, Westra JW, Rehen SK et al. Normal human pluripotent stem cell lines exhibit pervasive mosaic aneuploidy. PLoS ONE 6(8), e23018 (2011).

14. Rooney D. Human Cytogenetics: Constitutional Analysis. (3rd Edition). Oxford University Press, Oxford, UK (2001).

15. Hook EB. Exclusion of chromosomal mosaicism: tables of $90 \%, 95 \%$ and $99 \%$ confidence limits and comments on use. Am. J. Hum. Genet. 29(1), 94-97 (1977).

16. Miller DT, Adam MP, Aradhya S et al. Consensus statement: chromosomal microarray is a first-tier clinical diagnostic test for individuals with developmental disabilities or congenital anomalies. Am. J. Hum. Genet. 86(5), 749-764 (2010).

17. Merkle FT, Neuhausser WM, Santos D et al. Efficient CRISPR-Cas9-mediated generation of knockin human pluripotent stem cells lacking undesired mutations at the targeted locus. Cell Rep. 11(6), 875-883 (2015).

18. Merkle FT, Ghosh S, Kamitaki N et al. Human pluripotent stem cells recurrently acquire and expand dominant negative P53 mutations. Nature 545(7653), 229-233 (2017).

19. Forbes SA, Beare D, Boutselakis H et al. COSMIC: somatic cancer genetics at high-resolution. Nucleic Acids Res. 45(D1), D777-D783 (2017).

20. Forbes SA, Beare D, Bindal N et al. COSMIC: high-resolution cancer genetics using the Catalogue of Somatic Mutations in Cancer. Curr. Protoc. Hum. Genet. 91, 10.11.11-10.11.37 (2016).

21. Muller FJ, Goldmann J, Loser P, Loring JF. A call to standardize teratoma assays used to define human pluripotent cell lines. Cell Stem Cell 6(5), 412-414 (2010).

22. Buta C, David R, Dressel R et al. Reconsidering pluripotency tests: do we still need teratoma assays? Stem Cell Res. 11(1), 552-562 (2013).

23. Muller FJ, Schuldt BM, Williams R et al. A bioinformatic assay for pluripotency in human cells. Nat. Methods 8(4), 315-317 (2011).

24. Bouma MJ, Van Iterson M, Janssen B, Mummery CL, Salvatori DCF, Freund C. Differentiation-defective human induced pluripotent stem cells reveal strengths and limitations of the teratoma assay and in vitro pluripotency assays. Stem Cell Rep. 8(5), 1340-1353 (2017).

25. Paull D, Sevilla A, Zhou H et al. Automated, high-throughput derivation, characterization and differentiation of induced pluripotent stem cells. Nat. Methods 12(9), 885-892 (2015). 